\title{
Coenzyme $0_{10}$ therapy before cardiac surgery improves mitochondrial function and in vitro contractility of myocardial tissue
}

\author{
Franklin Rosenfeldt, MD, FRACS ${ }^{a, b}$ \\ Silvana Marasco, FRACS ${ }^{a}$ \\ William Lyon, MBBS ${ }^{a}$ \\ Michelle Wowk, BSc(Hons) ${ }^{\text {a }}$ \\ Freya Sheeran, BA, BSc(Hons) ${ }^{a}$ \\ Michael Bailey, MSc(Stats) ${ }^{b}$ \\ Donald Esmore, FRACS ${ }^{a}$ \\ Bruce Davis, FRACS ${ }^{a}$ \\ Adrian Pick, FRACS ${ }^{a}$ \\ Mark Rabinov, PhD, FRACS ${ }^{a}$ \\ Julian Smith, MSurg, FRACS \\ Phillip Nagley, PhD, DSc ${ }^{\mathrm{C}}$ \\ Salvatore Pepe, $\mathrm{PhD}^{\mathrm{a}}$
}

From The Cardiac Surgical Research Unit,
Department of Cardiothoracic Surgery, Al-
fred Hospital, the Baker Heart Research
Institute (Wynn Domain), and the Depart-
ment of Surgery, ${ }^{a}$ Monash University; the
Department of Epidemiology and Preven-
tative Medicine, ${ }^{\text {b }}$ Monash University; and
the Department of Biochemistry and Mo-
lecular Biology, ${ }^{c}$ Monash University, Mel-
bourne, Australia.

Supported by the National Heart Foundation of Australia and Blackmores Australia Pty Ltd.

Received for publication Sept 3, 2003; revisions requested March 15, 2004; accepted for publication March 25, 2004.

Address for reprints: Salvatore Pepe, $\mathrm{PhD}$, Baker Heart Research Institute, PO Box 6492, St Kilda Road Central, Melbourne VIC 8008, Australia (E-mail: spepe @ baker. edu.au).

J Thorac Cardiovasc Surg 2005;129:25-32 $0022-5223 / \$ 30.00$

Copyright $\odot 2005$ by The American Association for Thoracic Surgery

doi:10.1016/j.jtcvs.2004.03.034
Objectives: Previous clinical trials suggest that coenzyme $\mathrm{Q}_{10}$ might afford myocardial protection during cardiac surgery. We sought to measure the effect of coenzyme $\mathrm{Q}_{10}$ therapy on coenzyme $\mathrm{Q}_{10}$ levels in serum, atrial trabeculae, and mitochondria; to assess the effect of coenzyme $\mathrm{Q}_{10}$ on mitochondrial function; to test the effect of coenzyme $\mathrm{Q}_{10}$ in protecting cardiac myocardium against a standard hypoxia-reoxygentation stress in vitro; and to determine whether coenzyme $\mathrm{Q}_{10}$ therapy improves recovery of the heart after cardiac surgery.

Methods: Patients undergoing elective cardiac surgery were randomized to receive oral coenzyme $\mathrm{Q}_{10}(300 \mathrm{mg} / \mathrm{d})$ or placebo for 2 weeks preoperatively. Pectinate trabeculae from right atrial appendages were excised, and mitochondria were isolated and studied. Trabeculae were subjected to 30 minutes of hypoxia, and contractile recovery was measured. Postoperative cardiac function and troponin I release were assessed.

Results: Patients receiving coenzyme $\mathrm{Q}_{10}(\mathrm{n}=62)$ had increased coenzyme $\mathrm{Q}_{10}$ levels in serum $(P=.001)$, atrial trabeculae $(P=.0001)$, and isolated mitochondria $(P=.0002)$ compared with levels seen in patients receiving placebo $(\mathrm{n}=59)$. Mitochondrial respiration (adenosine diphosphate/oxygen ratio) was more efficient $(P=.012)$, and mitochondrial malondialdehyde content was lower $(P=.002)$ with coenzyme $\mathrm{Q}_{10}$ than with placebo. After 30 minutes of hypoxia in vitro, pectinate trabeculae isolated from patients receiving coenzyme $\mathrm{Q}_{10}$ exhibited a greater recovery of developed force compared with those in patients receiving placebo $(46.3 \%$ $\pm 4.3 \%$ vs $64.0 \% \pm 2.9 \%, P=.001)$. There was no between-treatment difference in preoperative or postoperative hemodynamics or in release of troponin I.

Conclusions: Preoperative oral coenzyme $\mathrm{Q}_{10}$ therapy in patients undergoing cardiac surgery increases myocardial and cardiac mitochondrial coenzyme $\mathrm{Q}_{10}$ levels, improves mitochondrial efficiency, and increases myocardial tolerance to in vitro hypoxia-reoxygenation stress. 


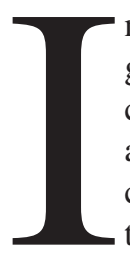

$\mathrm{n}$ the current era, patients referred for cardiac surgery have increasing numbers of risk factors, including previous angioplasty, myocardial failure, and old age. Age-associated cardiovascular changes adversely affect the preoperative state of the myocardium, rendering it more vulnerable to stresses ${ }^{1}$ such as those incurred during cardiac surgery and resulting in higher operative mortality and an increased incidence of postoperative complications. ${ }^{2,3}$

Coenzyme $\mathrm{Q}_{10}\left(\mathrm{CoQ}_{10}\right)$ is a lipid-soluble antioxidant and a key component of the mitochondrial electron transport chain for adenosine triphosphate (ATP) production. ${ }^{4,5}$ Myocardial $\mathrm{CoQ}_{10}$ content is reduced by cardiac failure and aging. ${ }^{6-8}$ Further reductions can be caused by 3-hydroxy-3methyl-glutaryl coenzyme A (HMG-CoA) reductase inhibitors, which have been shown to lower plasma and myocardial levels of $\mathrm{CoQ}_{10} \cdot{ }^{9-12}$ Our previous experimental work has shown that $\mathrm{CoQ}_{10}$ has the ability to protect the myocardium against ischemia-reperfusion injury ${ }^{8}$ and against aerobic pacing stress, especially in elderly hearts. ${ }^{13}$

Previous clinical trials have suggested that treatment with $\mathrm{CoQ}_{10}$ before cardiac surgery might improve postoperative cardiac function and reduce myocardial structural damage. ${ }^{14-19}$ However, many of these trials were limited by insufficient $\mathrm{CoQ}_{10}$ dosage or low patient numbers or were not randomized, double-blinded, and placebo controlled. Although some of these studies demonstrated increased serum levels, incorporation of $\mathrm{CoQ}_{10}$ into the myocardium and mitochondria was not studied. Thus the aim of the present study was to perform a prospective, randomized, double-blind trial of preoperative high-dose $\mathrm{CoQ}_{10}$ therapy $(300 \mathrm{mg} / \mathrm{d})$ in patients undergoing elective cardiac surgery on bypass to measure the effect of high-dose $\mathrm{CoQ}_{10}$ therapy on the following: (1) $\mathrm{CoQ}_{10}$ levels in serum, atrial myocardium, and mitochondria (dose efficacy); (2) mitochondrial respiration; and (3) capacity to protect atrial trabeculae against a standard hypoxia-reoxygentation stress in vitro (primary end point). We also sought to assess the effect of $\mathrm{CoQ}_{10}$ therapy on postsurgical recovery of cardiac pump function, troponin release, and quality of life (secondary end points).

\section{Methods}

\section{Patient Enrollment}

Patients presenting for elective first-time coronary artery bypass graft or valve operations with cardiopulmonary bypass between May 1998 and July 2000 at the Alfred Hospital were eligible for inclusion in the study. Exclusion criteria were reoperation, urgent or emergency procedures, current therapy with warfarin or antioxidants, and recent myocardial infarction $(\leq 6$ weeks before the operation).

Patients undergoing elective coronary bypass surgery who provided informed consent were randomized (random numbers in blocks of 4) to receive either oral $\mathrm{CoQ}_{10}(300 \mathrm{mg} / \mathrm{d})$ or placebo in a double-blinded fashion before the operation, commencing at the time they were placed on the preoperative waiting list. The study protocol was approved by The Alfred Hospital Human Ethics Committee.

\section{Atrial Appendage Harvest and Dissection}

Atrial appendages discarded during atrial cannulation before cardiopulmonary bypass were stored in bicarbonate buffer $(\mathrm{NaCl}$, $125.8 \mathrm{mmol} / \mathrm{L} ; \mathrm{KCl}, 3.6 \mathrm{mmol} / \mathrm{L} ; \mathrm{MgSO}_{4}, 0.6 \mathrm{mmol} / \mathrm{L} ; \mathrm{NaH}_{2} \mathrm{PO}_{4}$, $1.3 \mathrm{mmol} / \mathrm{L} ; \mathrm{NaHCO}_{3}, 25.0 \mathrm{mmol} / \mathrm{L}$; glucose, $11.2 \mathrm{mmol} / \mathrm{L}$; and $\mathrm{CaCl}_{2}, 2.5 \mathrm{mmol} / \mathrm{L}$ equilibrated with $95 \% \mathrm{O}_{2}$ and $5 \% \mathrm{CO}_{2}$ to $\mathrm{pH}$ 7.4) containing $30 \mathrm{mmol} / \mathrm{L} \mathrm{2,3}$ butanedione monoxime. All trabeculae were dissected out for isolation of mitochondria, and up to 6 pectinate trabeculae $(\sim 1 \mathrm{~mm}$ in diameter, $<7 \mathrm{~mm}$ in length) per patient were selected for isometric contraction experiments.

\section{Mitochondrial Isolation and Respiration}

Mitochondria were isolated from atrial trabeculae according to previously reported methods. ${ }^{20}$ Mitochondrial $\mathrm{O}_{2}$ consumption was measured by using a miniature, custom-designed, Clarke-type $\mathrm{O}_{2}$ electrode in a glass chamber maintained at $37^{\circ} \mathrm{C}$. Digital data acquisition and consumption rate analyses were performed with customized software. Mitochondria were suspended in sucrose buffer $\left(0.3 \mathrm{~mol} / \mathrm{L}\right.$ sucrose, $5 \mathrm{mmol} / \mathrm{L} \mathrm{KH}_{2} \mathrm{PO}_{4}, 5 \mathrm{mmol} / \mathrm{L} 3-(N-$ morpholino)propanesulfonic acid (MOPS), $1 \mathrm{mmol} / \mathrm{L}$ ethylenediamine tetraacetic acid, and $0.1 \%$ bovine serum albumin-fatty acid free) and were added to the glass chamber at a protein concentration of $1 \mathrm{mg} / \mathrm{mL}$. Pyruvate-malate $(2.5 \mathrm{mmol} / \mathrm{L}$ and $0.5 \mathrm{mmol} / \mathrm{L}$, respectively) was used as a source of electrons for the respiratory chain, whereas $0.34 \mathrm{mmol} / \mathrm{L}$ adenosine diphosphate (ADP) was used to release the accumulation of electrons and drive ATP synthesis at Complex V. The proton uncoupler carbonyl cyanide $p$-trifluoromethoxyphenylhydrazone (FCCP) $(1 \mu \mathrm{mol} / \mathrm{L})$ was used to determine the maximum $\mathrm{O}_{2}$ consumption rate. Sodium cyanide $(10 \mathrm{mmol} / \mathrm{L})$ was used to block mitochondria-specific $\mathrm{O}_{2}$ consumption at the conclusion of each experiment.

\section{$\mathrm{CoQ}_{10}$ and Malondialdehyde Assays}

Total $\mathrm{CoQ}_{10}$ was measured by means of UV spectrophotometric high-performance liquid chromatography analysis after solvent extraction of serum or isolated membranes with a mixture of hexanes and ethanol (1:5:2). $\mathrm{CoQ}_{10}(5 \mu \mathrm{g}$ per sample) was used as the internal standard to determine the extraction efficiency. Samples and standards were measured on Waters high-performance liquid chromatography at $280 \mathrm{~nm}$ (20 minutes' run time) by using a 39:35:26 mixture of methanol, isopropanol, and acetonitrile as the isocratic mobile phase through a $\mathrm{C} 18$ Radial Pak, $8 \mathrm{~mm}$ inner diameter, 4- $\mu \mathrm{m}$ particle column (Waters). $\mathrm{CoQ}_{6}$ and $\mathrm{CoQ}_{10}$ standards (Sigma) ranged from 0.25 to $4 \mu \mathrm{g}$ and 0.1 to $1.0 \mu \mathrm{g}$, respectively. The areas under the peaks of the samples were compared with those of the standards to determine $\mathrm{CoQ}_{10}$ content. Values were adjusted to the efficiency of $\mathrm{CoQ}_{6}$ extraction and were expressed as micrograms of $\mathrm{CoQ}_{10}$ per milligrams of mitochondrial protein or micrograms of $\mathrm{CoQ}_{10}$ per milliliters of serum.

Malondialdehyde (MDA) formation in isolated mitochondrial membranes was measured spectrophotometrically as an index of the degree of lipid peroxidation. A commercial colorimetric assay (catalog no. 437634, Calbiochem) was used to specifically mea- 
sure the condensation between one molecule of MDA with 2 molecules of N-methyl-2-phenylindole to yield a stable chromophore at $586 \mathrm{~nm}$.

\section{Atrial Trabecular Function in Vitro}

Trabeculae were attached to organ bath force transducers and were stimulated electrically at $2 \mathrm{~Hz}$ in oxygenated bicarbonate buffer, as previously described. ${ }^{21}$ After baseline measurements of contractility, hypoxia was induced by replacing the $95 \% \mathrm{O}_{2} / 5 \% \mathrm{CO}_{2}$ in the organ bath with $95 \% \mathrm{~N}_{2} / 5 \% \mathrm{CO}_{2}$. After 30 minutes of hypoxia $\left(\mathrm{Po}_{2}, 45 \pm 3 \mathrm{~mm} \mathrm{Hg}\right)$, the trabeculae were reoxygenated, and contractile recovery was continuously measured. Posthypoxic recovery of developed force (at 30 minutes) was expressed as a percentage of the prehypoxic value. Measurements were also made of resting force, time to peak contraction, and time to $50 \%$ relaxation of peak force.

\section{Clinical Procedures}

Blood samples were taken for the measurement of $\mathrm{CoQ}_{10}$ levels before and after therapy (in the operating room before cardiopulmonary bypass). Coronary bypass surgery was performed by using a standard on-pump surgical technique. Myocardial preservation was attained by means of either intermittent tepid blood cardioplegia with St Thomas' potassium-magnesium solution containing $15 \mathrm{mmol} / \mathrm{L}$ aspartate at $20^{\circ} \mathrm{C}$ to $25^{\circ} \mathrm{C}$ ( 3 surgeons) or by means of cold crystalloid St Thomas' cardioplegia at $4^{\circ} \mathrm{C}$ with topical cooling ( 3 surgeons). Blood samples were taken for measurement of troponin I levels 4 and 24 hours after admission to the intensive care unit.

\section{Hemodynamic Monitoring}

A pulmonary artery thermodilution catheter (Edwards Lifescience) was inserted before the operation for measurement of pulmonary capillary wedge pressure and cardiac output. Measurements were taken in the operating room before cardiopulmonary bypass and after bypass just before closure of the sternotomy and again in the intensive care unit 4 hours after cardiac surgery. Heart rate and mean arterial blood pressure were also recorded and used to calculate left ventricular stroke work index. Inotropic drug therapy was instituted according to standardized criteria.

\section{Quality-of-life Measures}

The Medical Outcome Study Short Form 36-item health status questionnaire (SF36) was used to assess the quality of life after the operation. The SF36 is a self-administered questionnaire that assesses 8 variables related to physical and mental state, including functional status, emotional and social well-being, and overall evaluation of health. ${ }^{22}$ The survey was sent to all patients, and replies were obtained in the first cohort of 60 patients at a median of 27 months. The physical function parameters were combined to produce a Physical Component Summary, and the mental function parameters were combined to produce a Mental Component Summary.

\section{Statistics}

Sample size calculations showed that to detect a $10 \%$ betweengroup difference in the posthypoxic recovery of pectinate trabeculae developed force with a power of $80 \%$ and a significance level
TABLE 1. Patient demographics and length of therapy

\begin{tabular}{lccc}
\hline & $\begin{array}{c}\text { Placebo } \\
(\mathbf{n}=\mathbf{5 9})\end{array}$ & $\begin{array}{c}\mathbf{C o O}_{\mathbf{1 0}} \\
(\mathbf{n}=\mathbf{6 2})\end{array}$ & $\boldsymbol{P}$ value \\
\hline Age $(\mathbf{y})^{*}$ & $68(60-74)$ & $67(56-73)$ & .31 \\
Male (\%) & 85 & 76 & .32 \\
Remote MI (\%) & 43 & 31 & .23 \\
LV function grade & $2.2 \pm 0.1$ & $2.1 \pm 0.1$ & .68 \\
Hypertension (\%) & 62 & 57 & .63 \\
Diuretic (\%) & 21 & 10 & .13 \\
ACE inhibitor (\%) & 41 & 26 & .11 \\
$\beta$-blocker (\%) & 38 & 50 & .23 \\
Days of therapy & $13.5 \pm 1.5$ & $14.0 \pm 1.1$ & .83
\end{tabular}

Left ventricular function was graded from the angiographic ejection fraction on a 4-point scale: 1, normal (ejection fraction $>60 \%$ ); 2 , mildly impaired (ejection fraction $46 \%$ to $60 \%$ ); 3 , moderately impaired (ejection fraction $30 \%$ to $45 \%$ ); 4 , severely impaired (ejection fraction $<30 \%$ ).

$\mathrm{CoO}_{10}$, Coenzyme $\mathrm{Q}_{10}$; remote $\mathrm{MI}$, myocardial infarction more than 2 months before surgical intervention; $L V$, left ventricular; $A C E$, angiotensinconverting enzyme.

${ }^{*}$ Median (50\% confidence limits).

of .05 would require 94 patients per group. To detect a $15 \%$ difference would require 48 patients per group. Variables are expressed as means \pm SEM. Log transforms were used to normalize length of stay and troponin levels. The $t$ test was used for between-group differences in patient demographics, operative variables, $\mathrm{CoQ}_{10}$ levels, trabecular contractile function, and quality-of-life scores. The $\chi^{2}$ and Fisher exact tests were used for categoric variables. Multivariable analysis was used to test for the influence of preoperative variables on recovery of trabecular contractile function and troponin I release and for the influence of preoperative and operative variables on length of hospital stay. Values are reported as means \pm SEM unless otherwise stated. Statistical significance was defined as $P<.05$.

\section{Results}

\section{Clinical Variables}

One hundred twenty-one patients were enrolled in the study. There were no significant differences at baseline between the 2 treatment groups (Table 1). The mean length of treatment in each group was approximately 2 weeks. The operative procedures were similar in both groups (Table 2), being predominantly coronary artery bypass graft surgery or valve replacement. The 6 operating surgeons were distributed equally between the 2 groups $(P=.85)$. There were no deaths in the hospital.

\section{In Vitro Results}

Co $Q_{10}$ levels. At baseline, serum $\mathrm{CoQ}_{10}$ levels were similar in both groups (Table 3). After therapy, serum $\mathrm{CoQ}_{10}$ levels in the $\mathrm{CoQ}_{10}$ group were approximately 4 times greater than those in the placebo group $(P=.001)$. In atrial myocardium the $\mathrm{CoQ}_{10}$ concentration was 2.5 times higher in the $\mathrm{CoQ}_{10}$ group than in the placebo group $(P=$ .0001). The mitochondrial $\mathrm{CoQ}_{10}$ concentration was 2.4 
TABLE 2. Operative variables

\begin{tabular}{lccc}
\hline & $\begin{array}{c}\text { Placebo } \\
(\mathbf{n}=\mathbf{5 9})\end{array}$ & $\begin{array}{c}\mathbf{C o O}_{\mathbf{1 0}} \\
(\mathbf{n}=\mathbf{6 2})\end{array}$ & $\boldsymbol{P}$ value \\
\hline CABG alone (\%) & 93 & 87 & .43 \\
Mean grafts & $2.9 \pm 0.1$ & $3.2 \pm 0.1$ & .17 \\
CPB time (min)* & $91(70-107)$ & $91(75-106)$ & .61 \\
CC time (min)* & $57(42-73)$ & $56(47-75)$ & .77 \\
TBC & $39(66 \%)$ & $43(69 \%)$ & .85 \\
\hline
\end{tabular}

$\mathrm{CoO}_{10}$, Coenzyme $0_{10} ; C A B G$, coronary artery bypass grafting; $C P B$, cardiopulmonary bypass; $C C$, crossclamp; $T B C$, tepid blood cardioplegia.

${ }^{*}$ Median (50\% confidence limits).

TABLE 3. Serum, atrial myocardium, and mitochondrial $\mathrm{CoO}_{10}$ levels

\begin{tabular}{llll}
\hline $\mathbf{C o}_{\mathbf{1 0}}$ measure & \multicolumn{1}{c}{ Placebo } & \multicolumn{1}{c}{$\mathbf{C o 0}_{\mathbf{1 0}}$} & $\boldsymbol{P}$ value \\
\hline Serum baseline* & $0.38 \pm 0.02$ & $0.39 \pm 0.02$ & .98 \\
Serum after therapy & $0.42 \pm 0.03$ & $1.59 \pm 0.06$ & .001 \\
Myocardium after therapy $\dagger$ & $17.2 \pm 1.4$ & $43.7 \pm 3.1$ & .0001 \\
Mitochondria after therapy $\ddagger$ & $4.04 \pm 0.71$ & $9.53 \pm 0.90$ & .0002
\end{tabular}

$\mathrm{Co}_{10}$, Coenzyme $\mathrm{Q}_{10}$.

*The normal range of serum $\mathrm{CoO}_{10}$ in healthy individuals is 0.5 to $1.0 \mu \mathrm{g} / \mathrm{mL}$. $\mathrm{CoO}_{10}$ units are given for serum as micrograms per milliliter, for atrial myocardium as micrograms per gram of wet weight, and for atrial mitochondria as micrograms per milligram of protein.

tPlacebo, $\mathrm{n}=56 ; \mathrm{CoO}_{10}, \mathrm{n}=51$.

¥Placebo, $\mathrm{n}=10 ; \mathrm{CoO}_{10}, \mathrm{n}=10$.

times greater in the $\mathrm{CoQ}_{10}$ group than in the placebo group $(P=.0002)$.

Mitochondrial respiration and lipid peroxidation. Coupled oxygen consumption (state III) in isolated myocardial mitochondria was significantly lower in the $\mathrm{CoQ}_{10}$ group $\left(49.0 \pm 2.7 \mathrm{vs} 72.2 \pm 3.7 \mathrm{ng} \mathrm{O}\right.$ atoms $\cdot \mathrm{min}^{-1} \cdot \mathrm{mg}^{-1}$ protein, $P=.011$ ) than in the placebo group (Figure $1, A$ ). The amount of oxygen consumed after addition of 0.34 $\mathrm{mmol} / \mathrm{L}$ ADP was used to calculate the ADP/O ratio after correction for contaminating adenosine monophosphate. This is a stoichiometric index of the amount of ATP produced (ADP consumed) per mole of oxygen used and is indicative of efficiency in ATP production. For the $\mathrm{CoQ}_{10}$ group, the ADP/O ratio $(2.04 \pm 0.2)$ was significantly higher than for placebo group mitochondria $(1.17 \pm 0.2 ; P$ $=.012 ;$ Fig $1, B)$. Fig $1, C$, demonstrates significantly lower accumulation of the lipid peroxidation product MDA in mitochondrial membranes in the $\mathrm{CoQ}_{10}$ group $(0.9 \pm 0.04$ $\mathrm{nmol} / \mathrm{mg}$ protein) than in the placebo group $(1.6 \pm 0.12$ $\mathrm{nmol} / \mathrm{mg}$ protein, $P=.002$ ).

Trabecular contractile function. At baseline, there were no differences in developed force, resting force, or time to $50 \%$ relaxation between the groups (Table 4). After hypoxia and reoxygenation, the recovery of developed force in the $\mathrm{CoQ}_{10}$ group $(64.0 \% \pm 2.9 \%)$ was greater than in the placebo group $(46.3 \% \pm 4.3 \%, P=.001$, Figure 2$)$. There
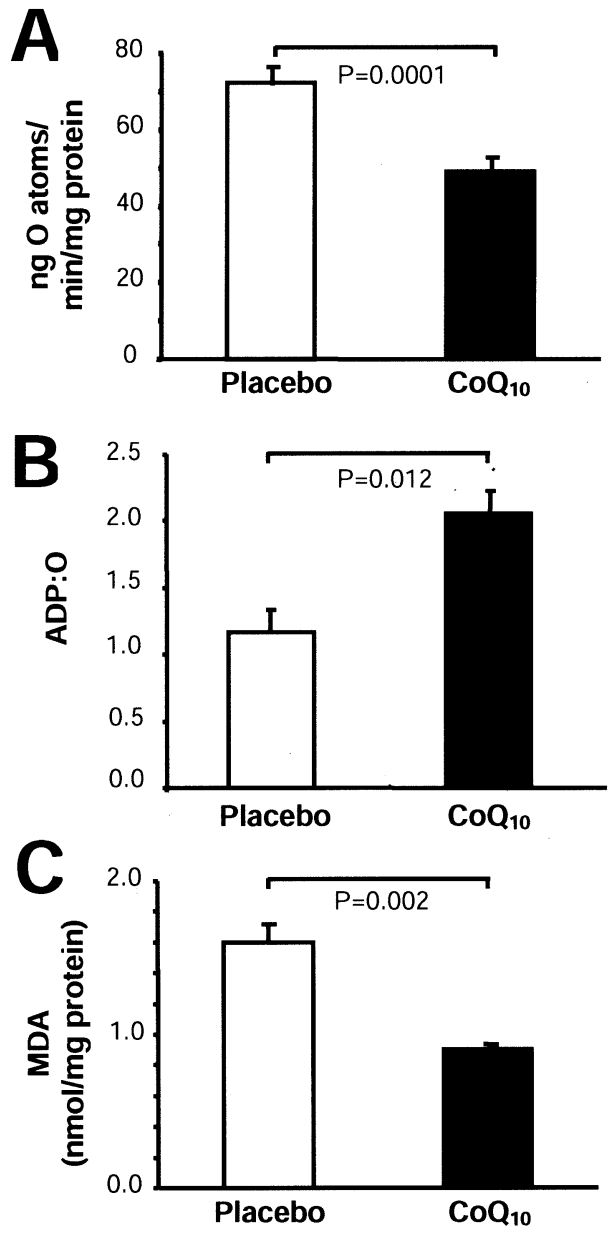

Figure 1. A, Coupled $\mathrm{O}_{2}$ consumption state III respiration in isolated human mitochondria during oxidation of pyruvate (2.5 $\mathrm{mmol} / \mathrm{L})$ plus malate $(0.5 \mathrm{mmol} / \mathrm{L})$ at $37^{\circ} \mathrm{C}$. B, The efficiency of energy production expressed as a stochiometric ratio of ADP consumed during ATP production per atom of oxygen consumed. C, The concentration of the lipid peroxidation product MDA in isolated human mitochondria.

were no between-group differences in resting force or time to $50 \%$ relaxation (Table 4). Multivariate analysis identified only treatment group as a predictor of recovery of developed force.

\section{Clinical Results}

Hemodynamics. Preoperative hemodynamic performance was similar for both groups, as were hemodynamic measurements in the operating room after discontinuation of bypass and stabilization (Table 5). Comparing postbypass values with prebypass values across both groups showed an increase in heart rate (median, 65 beats/min [50\% confidence limit, $55-76$ beats/min] to 90 beats/min [ $85-95$ beats/ $\min$ ], $P=.001$ ), an increase in cardiac index (from $2.6 \mathrm{~L}$. $\min ^{-1} \cdot \mathrm{m}^{-2}\left[2.1-3.0 \mathrm{~L} \cdot \min ^{-1} \cdot \mathrm{m}^{-2}\right]$ to $3.0 \mathrm{~L} \cdot \min ^{-1}$. 
TABLE 4. In vitro contractile function of isolated atrial trabeculae

\begin{tabular}{lccc}
\hline & $\begin{array}{c}\text { Placebo } \\
\text { (n= 20) }\end{array}$ & $\begin{array}{c}\mathbf{C o O}_{\mathbf{1 0}} \\
(\mathbf{n}=\mathbf{2 6})\end{array}$ & $\boldsymbol{P}$ value \\
\hline $\begin{array}{l}\text { Developed force } \\
\quad \text { Baseline (g) }\end{array}$ & $1.02 \pm 0.12$ & $1.16 \pm 0.07$ & .31 \\
$\quad$ After hypoxic recovery (\%) & $46.3 \pm 4.3$ & $64.0 \pm 2.9$ & .001 \\
Resting force & & & \\
$\quad$ Baseline (g) & $0.4 \pm 0.04$ & $0.5 \pm 0.06$ & .18 \\
$\quad$ After hypoxic recovery (\%) & $92.0 \pm 6.2$ & $86.7 \pm 2.5$ & .49 \\
Time to 50\% relaxation & & & \\
$\quad$ Baseline (ms) & $104.2 \pm 5.9$ & $104.5 \pm 3.7$ & .96 \\
$\quad$ After hypoxic recovery (\%) & $89.1 \pm 7.1$ & $85.2 \pm 2.4$ & .85 \\
\hline
\end{tabular}

$\mathrm{CoO}_{10}$, Coenzyme $\mathrm{Q}_{10}$.

$\left.\mathrm{m}^{-2}\left[2.7-3.4 \mathrm{~L} \cdot \min ^{-1} \cdot \mathrm{m}^{-2}\right], P=.001\right)$; a reduction in stroke work index (from $31 \mathrm{~g} . \mathrm{m} / \mathrm{m}^{2}$ per beat $\left[29-39 \mathrm{~g} . \mathrm{m} / \mathrm{m}^{2}\right.$ per beat] to $29 \mathrm{~g} \cdot \mathrm{m} / \mathrm{m}^{2}$ per beat $\left[23-34 \mathrm{~g} . \mathrm{m} / \mathrm{m}^{2}\right.$ per beat], $P$ $=.003)$, and a reduction in systemic vascular resistance (from 1187 dynes/s [993-1428 dynes/s] to 886 dynes/s [773-1012 dynes/s], $P=.001$ ). However, there were no between-group differences in postbypass versus prebypass values, except for a decrease in systemic vascular resistance that was greater in the placebo group than in the $\mathrm{CoQ}_{10}$ group $(P=.029)$. We tested for an effect of cardioplegia type on postbypass to prebypass hemodynamics. There was no effect on any of the parameters measured. Also, 4 hours after surgical intervention, there was no difference between treatment groups in any of the individual hemodynamic measurements. The incidence of inotropic drug use in the 2 groups was not significantly different $\left(\mathrm{CoQ}_{10}\right.$ group, $24 \%$; placebo group, 33\%; $P=.39$ ).

Troponin I release. Troponin I release measured 4 hours after the operation was $43.3 \pm 1.2 \mu \mathrm{g} / \mathrm{L}$ in the $\mathrm{CoQ}_{10}$ group and $44.2 \pm 1.2 \mu \mathrm{g} / \mathrm{L}$ in the placebo group $(P=.87)$, and after 24 hours, it was $14.1 \pm 1.2 \mu \mathrm{g} / \mathrm{L}$ in the $\mathrm{CoQ}_{10}$ group and $13.6 \pm 1.2 \mu \mathrm{g} / \mathrm{L}$ in the placebo group $(P=.64)$. Univariate analysis of the determinants of troponin release over the 2 time points indicated significant influences of surgeon's technique and operation type but not age or $\mathrm{CoQ}_{10}$ treatment (Table 6). It was not possible to separate the effect of surgeon's technique from cardioplegia type because each surgeon used only one type of cardioplegia: surgeons 1,4 , and $5(\mathrm{n}=48)$ used crystalloid cardioplegia, and surgeons 2, 3, and $6(\mathrm{n}=73)$ used blood cardioplegia. Troponin release was significantly higher $(P<.0001)$ in the cold crystalloid cardioplegia user group $(35.0 \pm 1.2 \mu \mathrm{g} / \mathrm{L})$ than in the tepid blood cardioplegia user group (17.2 \pm 1.2 $\mu \mathrm{g} / \mathrm{L})$. The 2 types of cardioplegia were equally distributed between the 2 treatment groups and were therefore unlikely to have influenced the $\mathrm{CoQ}_{10}$ effect. Multivariate analysis showed significant influences on troponin I release of surgeon's technique, operation type (coronary bypass versus valve procedure), and bypass time.

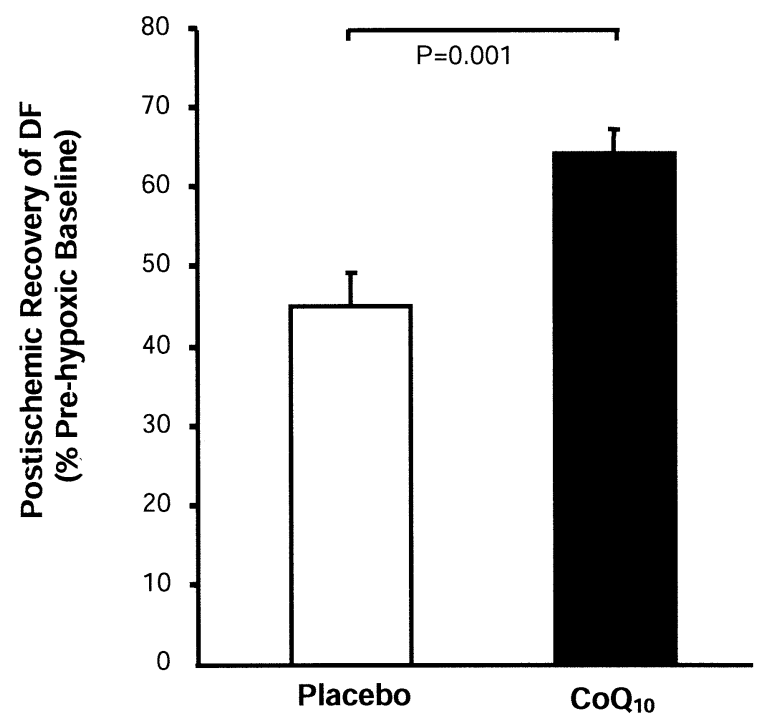

Figure 2. Contractile recovery of developed force in atrial pectinate trabeculae after $\mathbf{3 0}$ minutes of hypoxia.

Length of hospital stay. The median postoperative length of stay in the $\mathrm{CoQ}_{10}$ group was 7.0 days (interquartile range, 5.0-9.0 days), and in the placebo group, the median stay was 6.0 days (interquartile range, 5.0-8.0 days). Significant univariate predictors of postoperative hospital length of stay were age $\left(r^{2}=0.07, P=.0035\right)$, cardiopulmonary bypass time $\left(r^{2}=0.11, P=.0002\right)$, and crossclamp time $\left(r^{2}=0.08, P=.0013\right)$ but not $\mathrm{CoQ}_{10}$ treatment $\left(r^{2}=\right.$ $0.002, P=.58)$. Multivariate analysis showed only age $(P$ $=.0027)$ as a predictor of length of hospital stay.

\section{Late Follow-up}

At a median follow-up time of 37 months (interquartile range, 25-39 months), there were 5 late deaths: 4 (3 noncardiac and 1 cardiac) in the $\mathrm{CoQ}_{10}$ group and 1 (noncardiac) in the placebo group $(P=.16)$. Quality-of life assessment (SF36 questionnaire) of the first 60 patients at a median of 27 months (93\% complete) showed a significantly better $(+13 \%)$ Physical Component Summary in the $\mathrm{CoQ}_{10}$ group $\left(\mathrm{CoQ}_{10}\right.$ group, $47.5 \pm 1.6$; placebo group, $42.0 \pm 2.1 ; P=.046$ [higher SF36 scores indicate a greater quality of life]). No significant difference was evident in the Mental Component Summary $\left(\mathrm{CoQ}_{10}\right.$ group, $51.2 \pm 1.3$; placebo group, $51.3 \pm 1.1 ; P=.92$ ).

\section{Discussion}

Cardiac surgery involves multiple stresses to the myocardium that contribute to cellular energy depletion. In the intraoperative period there is ischemia-reperfusion injury caused by aortic crossclamping. In the postoperative period there is hypoxia caused by respiratory insufficiency and aerobic stress (high oxygen-demand stress) caused by post- 
TABLE 5. Prebypass and postbypass hemodynamics

\begin{tabular}{|c|c|c|c|c|c|c|}
\hline & \multicolumn{3}{|c|}{ Prebypass } & \multicolumn{3}{|c|}{ Postbypass } \\
\hline & Placebo & $\mathrm{CoO}_{10}$ & $P$ value & Placebo & $\mathrm{CoO}_{10}$ & $P$ value \\
\hline HR (beats/min) & $68.1 \pm 2.9$ & $64.4 \pm 2.1$ & .15 & $92.0 \pm 1.9$ & $90.3 \pm 1.4$ & .44 \\
\hline $\mathrm{MAP}(\mathrm{mm} \mathrm{Hg})$ & $75.7 \pm 1.9$ & $73.4 \pm 1.5$ & .18 & $69.2 \pm 1.1$ & $69.7 \pm 1.1$ & .72 \\
\hline CVP (mm Hg) & $6.9 \pm 0.6$ & $7.7 \pm 0.4$ & .14 & $7.7 \pm 0.6$ & $8.3 \pm 0.5$ & .44 \\
\hline PCWP $(\mathrm{mm} \mathrm{Hg})$ & $9.4 \pm 0.6$ & $9.9 \pm 0.5$ & .28 & $9.7 \pm 0.5$ & $9.7 \pm 0.4$ & .99 \\
\hline $\mathrm{Cl}\left(\mathrm{L} \cdot \mathrm{min}^{-1} \cdot \mathrm{m}^{-2}\right)$ & $2.6 \pm 0.1$ & $2.5 \pm 0.1$ & .44 & $3.2 \pm 0.1$ & $3.1 \pm 0.01$ & .75 \\
\hline SVR (dynes/s) & $1261.6 \pm 63.4$ & $1143.7 \pm 49.1$ & .07 & $889 \pm 30$ & $1037 \pm 90$ & .08 \\
\hline SV (L/min) & $75.7 \pm 3.3$ & $74.5 \pm 3.0$ & .39 & $70.4 \pm 2.3$ & $70.1 \pm 3.0$ & .13 \\
\hline LVSWI (g-m/m² per beat) & $34.7 \pm 1.8$ & $32.3 \pm 1.6$ & .17 & $28.5 \pm 0.9$ & $29.3 \pm 1.1$ & .59 \\
\hline
\end{tabular}

Values are expressed as means \pm SEM.

$\mathrm{CoO}_{10}$, Coenzyme $\mathrm{Q}_{10} ; H R$, heart rate; $M A P$, mean arterial pressure; $C V P$, central venous pressure; $P C W P$, pulmonary capillary wedge pressure; $C l$, cardiac index; $S V R$, systemic vascular resistance; SV, stroke volume; LVSWI, left ventricular stroke work index.

TABLE 6. Determinants of troponin I release over the first 24 hours postoperatively

\begin{tabular}{|c|c|}
\hline Parameter & $P$ value \\
\hline \multicolumn{2}{|l|}{ Univariate predictors } \\
\hline Bypass time & .013 \\
\hline Surgeon's technique & .017 \\
\hline Operation type (valve vs CABG only) & .041 \\
\hline Age & .056 \\
\hline $\mathrm{CoO}_{10}$ treatment & .83 \\
\hline \multicolumn{2}{|l|}{ Multivariate predictors } \\
\hline Bypass time & .008 \\
\hline Surgeon's technique & .0001 \\
\hline Operation type & .074 \\
\hline
\end{tabular}

$C A B G$, Coronary artery bypass grafting; $\operatorname{Co} Q_{10}$, coenzyme $Q_{10}$.

operative tachyarrhythmias, such as atrial fibrillation. The effect of these stresses is further augmented by preoperative risk factors, such as advanced age, hypertension, and cardiac failure. . $^{1,23}$

Animal studies in a variety of models have shown that acute or chronic treatment with $\mathrm{CoQ}_{10}$ can protect the myocardium against injury induced by ischemia and reperfusion, ${ }^{24,25}$ free radicals, ${ }^{26}$ and calcium overload. ${ }^{27} \mathrm{We}$ have previously reported that $\mathrm{CoQ}_{10}$ pretreatment in rats confers myocardial protection against the high oxygendemand stress of rapid pacing, especially in aged individuals. ${ }^{13}$ We have also shown that isolated human myocardial trabeculae obtained from patients aged 34 to 89 years are also protected against ischemia-reperfusion injury when pre-exposed to $\mathrm{CoQ}_{10}$ suspension in vitro. ${ }^{8}$ Moreover, in this previous study myocardial tissue from elderly individuals showed increased susceptibility to injury, and the protective effect of $\mathrm{CoQ}_{10}$ was greatest in these elderly tissues. These in vitro effects of $\mathrm{CoQ}_{10}$ followed rapid uptake of $\mathrm{CoQ}_{10}$ into sarcolemmal and mitochondrial membranes. We therefore postulated that sustained oral administration of $\mathrm{CoQ}_{10}$ to cardiac patients would increase myocardial and mitochondrial $\mathrm{CoQ}_{10}$ content, improve energy production, and confer cellular protection against oxidative stress. These benefits at a myocardial level might be detectable in terms of improvements in cardiac function and rate of recovery in the postoperative period.

In the present study the 2 treatment groups were comparable in terms of preoperative risk factors, and both were elderly (Table 1). Both treatment groups were subjected to the same intraoperative stresses in terms of duration of aortic crossclamping time and cardiopulmonary bypass and extent of surgical procedure.

\section{Myocardial Effects of $\mathrm{CoQ}_{10}$ Pretreatment}

Mitochondria isolated from atrial trabeculae exhibited an increased $\mathrm{CoQ}_{10}$ concentration in the $\mathrm{CoQ}_{10}$ group compared with the placebo group and had greater efficiency of oxygen consumption during energy production. The higher ratio of ADP:O seen in the $\mathrm{CoQ}_{10}$ group compared with the placebo group demonstrated that $\mathrm{CoQ}_{10}$ pretreatment afforded preservation of more efficient oxidative phosphorylation (ATP production), which is required to support in vitro posthypoxic contractile function and postoperative pump function. Associated with these effects, mitochondrial membranes from the $\mathrm{CoQ}_{10}$ group contained reduced levels of the lipid peroxidation product MDA compared with placebo, which indicates increased resistance to oxidative injury consistent with higher levels of $\mathrm{CoQ}_{10}$ in these membranes. These effects demonstrate the multiple molecular roles of $\mathrm{CoQ}_{10}$, in particular as an electron carrier, transferring electrons from nicotinamide adenine dinucleotide (NADH) dehydrogenase and succinate dehydrogenase to the cytochromes in the inner mitochondrial membrane during oxidative phosphorylation and as a free radical scavenger that inhibits lipid peroxidation. ${ }^{14,24}$

More recently, it has been shown that $\mathrm{CoQ}_{10}$ also specifically binds to a site in the inner mitochondrial membrane that inhibits the mitochondrial permeability transition pore. ${ }^{28}$ The mitochondrial permeability transition pore is a large conductance channel, which, when opened, can trigger 
the collapse of mitochondrial proton-motive force and membrane potential, leading to the disruption of ionic homeostasis and oxidative phosphorylation in cell death signaling pathways, particularly after ischemia and reperfusion. ${ }^{29}$ Protection afforded by $\mathrm{CoQ}_{10}$ from oxidative inactivation of creatine kinase and other key proteins during reperfusion is crucial in preserving energy metabolism and cardiac performance. ${ }^{14-19}$

Atrial trabeculae isolated from $\mathrm{CoQ}_{10}$-pretreated patients subjected to hypoxia-reoxygenation in vitro demonstrated greater recovery of developed force compared with placebo. This greater capacity for recovery of contractile function was associated with increased $\mathrm{CoQ}_{10}$ content in serum and myocardium after 2 weeks of oral $\mathrm{CoQ}_{10}$ therapy. Cardiac troponin I release was strongly influenced by the different surgeon's techniques, the type of operation, and the duration of cardiopulmonary bypass but not by preoperative $\mathrm{CoQ}_{10}$ therapy.

Of interest was an indication of improved subjective assessment of physical quality of life $(+13 \%)$ in the $\mathrm{CoQ}_{10}$ group compared with the placebo group when the first cohort of 60 patients was followed up 22 months postoperatively. However, these results should be interpreted with caution because of the fact that quality-of-life data were missing on $7 \%$ of the patients and that subjective improvement in physical quality of life does not necessarily indicate improved cardiac pump function.

\section{Previous $\mathrm{CoQ}_{10}$ Trials in Cardiac Surgery}

Previous randomized studies of $\mathrm{CoQ}_{10}$ treatment in cardiac surgery have shown significant effects but are limited by small patient numbers $(\leq 50) .{ }^{15-20}$ Of these, 3 studies ${ }^{15,17,18}$ showed an improvement in postoperative hemodynamics in $\mathrm{CoQ}_{10}$-treated patients. Zhou and colleagues ${ }^{14}$ showed that $\mathrm{CoQ}_{10}$ treatment significantly reduced plasma levels of MDA and creatine kinase (cardiac isoenzyme). Chen and associates ${ }^{19}$ showed improved preservation of myocardial ultrastructure in $\mathrm{CoQ}_{10}$-treated patients. However, Taggart and coworkers ${ }^{16}$ reported no benefit of oral $\mathrm{CoQ}_{10}$ pretreatment in a study of 20 randomized patients undergoing CABG who received $600 \mathrm{mg}$ of $\mathrm{CoQ}_{10}$ or placebo for 12 hours before surgical intervention. This latter result can be explained in terms of insufficient preoperative treatment time. Data from our preliminary studies indicated that despite a reasonably rapid increase in the blood $\mathrm{CoQ}_{10}$ level within 24 hours, approximately 1 week of treatment was required to show a significant increase in human myocardial $\mathrm{CoQ}_{10}$ concentration.

\section{Limitations of the Study}

There was no difference between groups in hemodynamic measurements made at rest in the operating room before or after cardiopulmonary bypass apart from a greater decrease in systemic vascular resistance (before vs after bypass) in the placebo group, which is probably a chance finding. Also, 4 hours after the operation, there were no between-group differences in hemodynamic measurements at rest. In the early postoperative period, any downward changes in cardiac function tend to be corrected by adjustments made in inotropic drug use by intensive care staff in response to perceived clinical need. Thus a useful indicator of major differences in postoperative function is inotropic drug use. However, this might be influenced by therapeutic aggressiveness by intensive care unit staff. We attempted to minimize therapeutic variability in our study by introducing fixed criteria for initiation of inotrope therapy in the intensive care unit. There was a small but nonsignificant difference in use of inotropic drugs in the 2 treatment groups $\left(\mathrm{CoQ}_{10}\right.$ group, $25 \%$; placebo group, $\left.33 \%\right)$. Sample size calculations showed that it would require a sample size of 530 per group for such a difference to reach significance.

There was no effect of $\mathrm{CoQ}_{10}$ on hemodynamics before or after surgical intervention. If transesophageal echocardiography had been available during the trial, pressure-volume loop measures would have been valuable. Reduction in postoperative release of troponin I would have been persuasive evidence of reduced intraoperative myocardial damage. However, any ability of $\mathrm{CoQ}_{10}$ to significantly reduce the release of troponin I was overshadowed by the confounding influences of cardiopulmonary bypass duration, operation type, and between-surgeon variation in techniques of surgical intervention and myocardial preservation. Thus greater patient numbers would be required to ensure sufficient statistical power to specifically overcome these confounding factors.

\section{Conclusions and Clinical Implications}

The important finding of the present study is the ability of orally administered $\mathrm{CoQ}_{10}$ to increase $\mathrm{CoQ}_{10}$ levels in human myocardium and mitochondria. The beneficial action of augmented $\mathrm{CoQ}_{10}$ levels involves increased protection of mitochondria and myofilaments against oxidative stress, with the consequent maintenance of efficient energy production and improved contractile recovery after hypoxiareoxygenation stress in vitro. To directly test the effect of $\mathrm{CoQ}_{10}$ on key postoperative patient outcomes, including more direct measures of recovery of cardiac performance and length of hospital stay, requires a well-resourced, large, multicenter trial with adequate statistical power to detect changes in clinically important end points.

We gratefully acknowledge the assistance of the perfusionists and operating room and intensive care nurses. We also thank Julie Mack, Yi Chen Xiao, and the Alfred Hospital's Departments of Pharmacy and Biochemical Pathology for their assistance (patient database management, data collation, patient randomization, and troponin I assays, respectively). 


\section{References}

1. Lakatta EG, Levy D. Arterial and cardiac aging: major shareholders in cardiovascular disease enterprises: part II: the aging heart in health: links to heart disease. Circulation. 2003;107:346-54.

2. Alexander KP, Peterson ED. Coronary artery bypass grafting in the elderly. Am Heart J. 1997;134:856-64.

3. Ivanov J, Weisel RD, David TE, Naylor CD. Fifteen-year trends in risk severity and operative mortality in elderly patients undergoing coronary artery bypass graft surgery. Circulation. 1998;97:673-80.

4. Frei B, Kim MC, Ames BN. Ubiquinol-10 is an effective lipid-soluble antioxidant at physiological concentrations. Proc Natl Acad Sci U S A. 1990;87:4879-83.

5. Turunen M, Swiezewska E, Chojnacki T, Sindelar P, Dallner G. Regulatory aspects of coenzyme Q metabolism. Free Radic Res. 2002;36:437-43.

6. Folkers K, Vadhanavikit S, Mortensen SA. Biochemical rationale and myocardial tissue data on the effective therapy of cardiomyopathy with coenzyme $\mathrm{Q}_{10}$. Proc Natl Acad Sci U S A. 1985;82:901-4.

7. Folkers K, Langsjoen $P$, Langsjoen $P H$. Therapy with coenzyme $Q_{10}$ of patients in heart failure who are eligible or ineligible for a transplant. Biochem Biophys Res Commun. 1992;182:247-53.

8. Rosenfeldt FL, Pepe S, Ou R, Mariani JA, Rowland MA, Nagley P, et al. Coenzyme $Q_{10}$ improves the tolerance of the senescent myocardium to aerobic and ischemic stress: studies in rats and in human atrial tissue. Biofactors. 1999;9:291-9.

9. Willis RA, Folkers K, Tucker JL, Ye CQ, Xia LJ, Tamagawa H. Lovastatin decreases coenzyme Q levels in rats. Proc Natl Acad Sci U $S$ A. 1990;87:8928-30.

10. Folkers K, Langsjoen P, Willis R, Richardson P, Xia LJ, Ye CQ, et al. Lovastatin decreases coenzyme Q levels in humans. Proc Natl Acad Sci U S A. 1990;87:8931-4.

11. Ghirlanda G, Oradei A, Manto A, Lippa S, Uccioli L, Caputo S, et al. Evidence of plasma $\mathrm{CoQ}_{10}$-lowering effect by $\mathrm{HMG}-\mathrm{CoA}$ reductase inhibitors: a double-blind, placebo-controlled study. J Clin Pharmacol. 1993;33:226-9.

12. Mortensen SA, Leth A, Agner E, Rohde M. Dose-related decrease of serum coenzyme $\mathrm{Q}_{10}$ during treatment with $\mathrm{HMG}-\mathrm{Co} \mathrm{A}$ reductase inhibitors. Mol Aspects Med. 1997;18(suppl):S137-44.

13. Rowland M, Nagley P, Linnane AW, Rosenfeldt FL. Coenzyme $Q_{10}$ treatment improves the tolerance of the senescent myocardium to pacing stress in the rat. Cardiovasc Res. 1998;40:165-73.

14. Zhou M, Zhi Q, Tang Y, Yu D, Han J. Effects of coenzyme $Q_{10}$ on myocardial protection during cardiac valve replacement and scavenging free radical activity in vitro. J Cardiovasc Surg. 1999;40:355-61.

15. Judy WV, Stogsdill WW, Folkers K. Myocardial preservation by therapy with coenzyme $\mathrm{Q}_{10}$ during heart surgery. Clin Investig. 1993; 71(suppl 8):155-61.

16. Taggart DP, Jenkins M, Hooper J, Hadjinikolas L, Kemp M, Hue D, et al. Effect of short-term supplementation with coenzyme $\mathrm{Q}_{10}$ on myocardial protection during cardiac operations. Ann Thorac Surg. 1996;61:829-33

17. Tanaka J, Tominage R, Yoshioshi M, Matsui K, Komori M, Sere A, et al. Coenzyme $\mathrm{Q}_{10}$ : the prophylactic effect on low cardiac out put following cardiac valve replacement. Ann Thorac Surg. 1982;33(2): 145-51.

18. Chello M, Mastroroberto P, Romano R, Bevacqua E, Pantaleo D, Ascione $\mathrm{R}$, et al. Protection by coenzyme $\mathrm{Q}_{10}$ from myocardial reperfusion injury during coronary artery bypass grafting. Ann Thorac Surg. 1994;58:1427-32.

19. Chen YF, Lin YT, Wu SC. Effectiveness of coenzyme $\mathrm{Q}_{10}$ on myocardial preservation during hypothermic cardioplegic arrest. J Thorac Cardiovasc Surg. 1994;107:242-7.

20. Pepe S, Tsuchiya N, Lakatta EG, Hansford RG. Modulation of cardiac membrane lipids and aging affect activation of pyruvate dehydrogenase and coupling of oxidative phosphorylation. Am J Physiol. 1999; 276:H149-58.

21. Mariani J, Ou R, Bailey M, Rowland M, Nagley P, Rosenfeldt F, et al. Tolerance to ischemia and hypoxia is reduced in aged human myocardium. J Thorac Cardiovasc Surg. 2000;120:660-7.

22. Chrispin PS, Scotton H, Roger J, Lloyd D, Ridley A. Short Form 36 in the intensive care unit: assessment of acceptability, reliability and validity of the questionnaire. Anaesthesia. 1997;52:15-23.

23. Misare B, Krukenkamp I, Levitsky S. Age-dependent sensitivity to unprotected cardiac ischemia: the senescent myocardium. J Thorac Cardiovasc Surg. 1992;103:60-5.

24. Matsushima T, Sudeda T, Matsuura Y, Kawasaki T. Protection by Coenzyme $\mathrm{Q}_{10}$ of canine myocardial reperfusion injury after preservation. J Thorac Cardiovasc Surg. 1992;103:945-51.

25. Maulik N, Yoshida T, Engelman R, Bagchi D, Otani H, Das D. Dietary coenzyme $\mathrm{Q}_{10}$ supplement renders swine hearts resistant to ischemiareperfusion injury. Am J Physiol. 2000;278:H1084-90.

26. Ferrara N, Abete P, Ambrosio G, Landino P, Caccese P, Cirillo P, et al. Protective role of chronic ubiquinone administration on acute cardiac oxidative stress. J Pharmacol Exp Ther. 1995;274:858-65.

27. Hano O, Thompson-Gorman SL, Zweier JL, Lakatta EG. Coenzyme $\mathrm{Q}_{10}$ enhances cardiac functional and metabolic recovery and reduces $\mathrm{Ca}^{2+}$ overload during postischemic reperfusion. Am J Physiol. 1994; 266:H2174-81.

28. Papucci L, Schiavone N, Witort E, Donnini M, Lapucci A, Tempestini A, et al. Coenzyme $Q_{10}$ prevents apoptosis by inhibiting mitochondrial depolarization independently of its free radical scavenging property. J Biol Chem. 2003;278:28220-8.

29. Di Lisa F, Canton M, Menabo R, Dodoni G, Bernardi P. Mitochondria and reperfusion injury. The role of permeability transition. Basic Res Cardiol. 2003;98:235-41. 